\title{
Adaptation of the BCR sequential extraction procedure for fractionation of potentially toxic elements in airborne particulate matter collected during routine air quality monitoring
}

\author{
Balarabe S Sagagia, ${ }^{a}$, Christine M Davidson ${ }^{a}$ and Andrew S Hursthouse ${ }^{c}$ \\ aWestCHEM, Department of Pure and Applied Chemistry, University of Strathclyde, 295 Cathedral Street, \\ GLASGOW G1 1XL, UK \\ ${ }^{b}$ Department of Chemistry, Kano University of Science and Technology, WUDIL, NIGERIA \\ 'School of Computing, Engineering and Physical Sciences, University of the West of Scotland, PAISLEY PA1 \\ 2BE, UK
}

\begin{abstract}
The Community Bureau of Reference (BCR) four-step sequential extraction has been adapted for fractionation of potentially toxic elements (PTE) in simulant airborne particulate matter (APM) samples presented on $47 \mathrm{~mm}$ filter dynamics measurement system (FDMS) filters as used in routine air quality monitoring. Simulants were prepared from an urban soil reference material and from BCR CRM 701, which is certified for analytes extractable by the BCR procedure. Analysis was performed by inductively coupled plasma mass spectrometry using an Agilent 7700x instrument. Fractionation patterns similar to the full-scale protocol were obtained when test portions as small as $0.0625 \mathrm{~g}$ were extracted in $2-3 \mathrm{~mL}$ of reagents. However, changing the extraction vessel used was found to affect the outcome. This highlights the operational nature of sequential extraction procedures and the need carefully to evaluate the effects of procedural modifications. When the method developed was applied to blank FDMS filters, large amounts of $Z n$ were detected, especially in step 3, the oxidisable fraction, and step 4, the residual fraction. Despite this, following blank-correction, fractionation patterns similar to certified values were obtained for BCR CRM 701, with overall recoveries ( $\Sigma$ (steps 1-4) ) of $84.2-113 \%$. Given the increased awareness of public health risks associated with poor air quality, a sequential extraction procedure specifically designed for use with APM samples collected during routine air quality represents a valuable tool for use in source apportionment and to improve understanding of human exposure to PTE through inhalation.
\end{abstract}

Keywords: sequential extraction; airborne particulate matter; potentially toxic elements; BCR; adaptation 
1. Introduction

In sequential extraction a series of reagents is applied consecutively in order of increasing harshness to the same solid sample to divide the potentially toxic element (PTE) content into fractions likely to have different mobility under environmental conditions. Although reagents are selected for their ability to target specific sample components (for example, specific soil mineral phases) it has been repeatedly demonstrated that sequential extraction is not entirely phase specific, but rather operationally defined [1]. Hence, the use of different reagents or conditions can give different results [2].

To improve comparability between laboratories conducting sequential extractions, the Community Bureau of Reference of the European Commission (BCR) in 1993 proposed a harmonised protocol [3]. This divided the PTE content into three fractions. Step 1 was the exchangeable, water and acid soluble fraction; step 2 the reducible fraction; and step 3 the oxidisable fraction. The original BCR procedure was revised [4] in 1999 to improve reproducibility. As well as modifying the reagent used in step 2, the revised BCR sequential extraction (Table 1) included an additional step, hot mineral acid digestion of the material remaining at the end of step 3. This was recommended so that mass balance could be performed with respect to results of a separate acid digestion of the sample.

The BCR sequential extraction is now widely used (featuring in almost 70 publications each year over the past decade according to Web of Science). It has been applied to numerous types of samples beyond the initial scope of soil and sediment, including coal [5], fertilisers [6], fly ash [7], municipal solid waste [8], and even medicinal plants [9] and herbal teas [10]. Ironically, the very popularity of the approach has to an extent obviated its creators' vision of a strictly prescribed protocol that would produce comparable results between laboratories! The extraction is frequently modified to suit new sample types or simply so that it can be carried out with the apparatus available in a particular laboratory. However, systematic tests are rarely performed to determine the effects of these procedural changes on results obtained. 
Exposure to airborne particulate matter (APM) has been identified as a risk factor for multiple health issues, including respiratory disease, cardio-vascular disease, and lung cancer [11,12]. Application of sequential extraction procedures to APM is desirable because it can provide information on their PTE content and lability, and hence contribute to the understanding of risk associated with inhalation of the particles $[13,14]$. A serious challenge, however, is that sampling devices used in routine air quality monitoring typically collect milligram quantities of APM, far less than the sample mass recommended $(1 \mathrm{~g})$ in the standard BCR protocol. Further, the APM is accumulated on a filter, the presence of which complicates sample handling and may introduce contamination.

One way to overcome low sample availability is to miniaturise the sequential extraction. For example, Sysalova and Szakalova [15] successfully fractionated As, $\mathrm{Cd}, \mathrm{Cr}, \mathrm{Mn}, \mathrm{Ni}, \mathrm{Pb}$ and $\mathrm{Zn}$ in $100 \mathrm{mg}$ samples of urban dusts collected in sedimentation chambers from road and subway tunnels in Prague, also reducing the extractant volume to maintain a 1:50 w/v ratio. In their study of $\mathrm{Pb}$ in suspended dusts from un-surfaced roadways in Missouri, Witt et al. [16] were able to apply the entire BCR procedure to the $>1 \mu \mathrm{m}$ particle size fraction collected in the container of a cyclonic fugitive dust sampler, but only step 1 to the $<1 \mu \mathrm{m}$ particle size fraction collected on the polypropylene filter in the sampler airstream. The authors considered the amount of material isolated from this filter - generally less than $0.1 \mathrm{~g}$ - insufficient for both sequential extraction and estimation of inhalation bioaccessibility. Dabek-Zlotorzynska et al. [17] used NIST SRM 1648 (urban particulate matter) to develop a version of the original BCR procedure [3] that required just $10 \mathrm{mg}$ of material. However, extraction was performed with ultrasoundassistance - a substantial departure from the recommended conventional shaking and analyte quantification by capillary electrophoresis. The method was later applied [18] to estimate the distribution of $\mathrm{Cd}, \mathrm{Cu}, \mathrm{Fe}, \mathrm{Mn}$ and $\mathrm{Zn}$ in $\mathrm{PM}_{2.5}$ (particles $<2.5 \mu \mathrm{m}$ in diameter) collected on Teflon ${ }^{\circledR}$ filters at urban sites in Canada.

An alternative approach is to deploy medium or high flow samplers to increase the amount of APM collected. Zhai et al. [19] used $90 \mathrm{~mm}$ diameter glass fibre filters and 
a flow rate of $100 \mathrm{~L} \mathrm{~min}^{-1}$ to collect $\mathrm{PM}_{2.5}$ in the city of Changsa, China. Sufficient material was obtained for fractionation of $\mathrm{Cd}, \mathrm{Cu}, \mathrm{Pb}$ and $\mathrm{Zn}$. Sun et al. [20] used an even higher flow rate $-1.05 \mathrm{~m}^{3} \mathrm{~min}$ - together with $20 \mathrm{~cm} \times 25 \mathrm{~cm}$ polytetrafluoroethylene filters to collect both total suspended particulates and PM2.5 for sequential extraction as part of their assessment of health risks associated with As, Cd, Co, Cr, Cu, Ni, Mn, Pb and Zn in Nanjing. In an opportunistic study, Sipos et al. [21] measured major elements and PTEs in total suspended particulates that had accumulated over a period of up to 15 months on filters in the air intake systems of four thermal power stations in Budapest. Although large quantities of sample were obtained, meaning both single and sequential extractions could be applied, the authors emphasised that their sampling method was unconventional and not readily transferable.

Large numbers of APM samples are collected by local and municipal authorities worldwide during routine air quality monitoring campaigns. These samples are typically assessed for just a few parameters e.g. mass of APM collected, black carbon, and then discarded. However, they represent a valuable unexplored resource for analytical geochemists. The tapered element oscillating microbalance (TEOM) and filter dynamics measurement system (FDMS) is widely used for continuous monitoring of ambient APM. Within the unit, the air is cycled between two paths: in one it goes directly to the TEOM (on which the mass of APM is measured); in the other it passes through a $47 \mathrm{~mm}$, Teflon-coated borosilicate TX-40 filter in the FDMS system [22]. If the BCR procedure could be applied to material collected on these FDMS filters then substantial new data could be obtained.

Outputs could support studies addressing fundamental environmental chemistry issues such as the chemical forms and solid-phase affinities of PTE in APM; facilitate research on APM sources and the impacts of anthropogenic activities on air quality; and enhance public health risk assessment through improved understanding of human exposure to PTE via inhalation. However, the extraction first needs to be adapted for application to low mass samples presented on FDMS filters, and the effects of these adaptations carefully evaluated to ensure performance is comparable to that obtained using the conventional BCR protocol. 
The aims of this study were to investigate the effects of stepwise scale-down of the BCR protocol on fractionation of a set of PTE typically found in the urban environment ( $\mathrm{Cr}, \mathrm{Cu}, \mathrm{Fe}, \mathrm{Mn}, \mathrm{Ni}, \mathrm{Pb}$ and $\mathrm{Zn}$ ) and then evaluate the applicability of the scaled-down protocol to simulant APM samples supported on FDMS TX-40 filters.

\section{Experimental}

All glassware and plastic vessels were soaked overnight in a $5 \%(\mathrm{v} / \mathrm{v})$ nitric acid bath and rinsed with distilled water before use. All reagents were of analytical grade apart from GPR nitric acid (Sigma-Aldrich, Gillingham, UK) used to make up the acid bath.

\subsection{Samples and sample preparation}

Method development was carried out using soil reference and certified reference materials because there are no APM CRM's with indicative or certified values for PTE extractable by the BCR sequential extraction. This was considered appropriate because soil-derived particles constitute a large proportion of APM (although lack some trace components such as combustion products).

The scale-down of the sequential extraction procedure was carried out using GLA URM, a sandy loam from an urban park in Glasgow that had been used as a secondary reference material for the EU URBSOIL project (EVK4-CT-2001-00053). The soil was sieved into seven particle size fractions: <45, 45-63, 63-90, 90-150, 150-250, 250-500 and 500-1000 $\mu \mathrm{m}$ using stainless steel pan sieves (Endecotts Ltd, UK) and a mechanical shaker. Unfortunately, it was not possible to obtain smaller particle size fractions, for example $\mathrm{PM}_{10}$, from the soil in sufficient quantity for study.

Simulant APM samples were prepared by using a plastic spatula to smear $0.125 \mathrm{~g}$ of BCR CRM 701 (lake sediment, particle size < $90 \mu \mathrm{m}$ ) onto $47 \mathrm{~mm}$ Pallflex TX-40 filters as used in TEOM-FDMS systems (borosilicate microfibers reinforced with 
woven glass cloth and bonded with polytetraflouroethylene, Air Monitors Limited, Gloucestershire, UK).

\subsection{Sample digestion}

A $20 \mathrm{~mL}$ aliquot of aqua regia, freshly prepared by mixing $\mathrm{HCl}$ and $\mathrm{HNO}_{3}$ (both from Sigma-Aldrich, $\mathrm{UK})$ in a 3:1 $(\mathrm{v} / \mathrm{N})$ ratio was added to $1 \mathrm{~g}$ of sample in a high-pressure vessel; left to stand partially-covered in a fume cupboard overnight to allow any vigorous reaction to subside; and then subjected to microwave-assisted digestion in a MARS Xpress system (CEM, Buckingham, UK). The operating conditions were: $1600 \mathrm{~W}$; ramp time from room temperature to $160^{\circ} \mathrm{C}=10 \mathrm{~min}$; hold time at $160^{\circ} \mathrm{C}=$ $20 \mathrm{~min}$. After cooling, the digests were filtered into $100 \mathrm{~mL}$ volumetric flasks. The filtrates were made up to the mark with distilled water, stored in a refrigerator, and diluted as required for analysis by inductively coupled plasma atomic emission spectrometry (ICP-AES). Samples were digested in triplicate along with a procedural blank.

Samples of BCR CRM 701 supported on FDMS filters were digested in $5 \mathrm{~mL}$ of aqua regia at $800 \mathrm{~W}$. A 20-min ramp time from room temperature to $160^{\circ} \mathrm{C}$ was used, followed by a $20 \mathrm{~min}$ hold at $160^{\circ} \mathrm{C}$. Digests were filtered into $10 \mathrm{~mL}$ flasks, made up to volume with distilled water, stored under refrigeration, and diluted 200 -fold for analysis by inductively coupled plasma mass spectrometry (ICP-MS).

\subsection{Sequential extraction}

The revised (1999) four-step BCR sequential extraction [4] was applied to the GLA URM. The protocol when processing a $1 \mathrm{~g}$ sample is outlined below. Full details and recommendations on how to carry out the BCR procedure are available in reference [4].

Step 1: Exchangeable, water and acid-soluble fraction

A $40 \mathrm{~mL}$ aliquot of $0.43 \mathrm{M}$ acetic acid (Sigma-Aldrich, Gillingham, UK) was added to $1 \mathrm{~g}$ of GLA URM in a centrifuge tube, sealed, and shaken for $16 \mathrm{~h}$ (overnight) at room temperature on a mechanical end-over-end shaker (GFL 3040, Burgwedel, 
Germany). The mixture was centrifuged at $3000 \mathrm{~g}$ for 20 minutes, then the supernatant was decanted and retained at $4{ }^{\circ} \mathrm{C}$ for analysis. The residue was washed by shaking for 15 minutes on the end-over-end shaker with $20 \mathrm{~mL}$ of distilled water. The mixture was again centrifuged at $3000 \mathrm{~g}$ for 20 minutes, but this time the supernatant was discarded.

\section{Step 2: Reducible fraction}

A $40 \mathrm{~mL}$ aliquot of freshly prepared and acidified $0.5 \mathrm{M}$ hydroxylammonium chloride (Fisher, Loughborough, UK) was added to the solid residue from step 1. The mixture was shaken and centrifuged as described for step 1 to obtain the extract for analysis.

Step 3: Oxidisable fraction

A $10 \mathrm{~mL}$ aliquot of $30 \%$ hydrogen peroxide (VWR, Leicestershire, UK) was added carefully, in small aliquots, to the solid residue from step 2 . The mixture was loosely covered and allowed to react at room temperature for $1 \mathrm{~h}$ with occasional manual shaking, then digested for a further $1 \mathrm{~h}$ at $85^{\circ} \mathrm{C}$, before removal of the lid and reduction of the volume to $<3 \mathrm{~mL}$. A further $10 \mathrm{~mL}$ of $\mathrm{H}_{2} \mathrm{O}_{2}$ was added, the mixture digested at $85^{\circ} \mathrm{C}$ for $1 \mathrm{~h}$, and then the volume reduced to $<1 \mathrm{~mL}$. Care was taken not to allow the sample to dry completely. Once cool, $50 \mathrm{~mL}$ of $1.0 \mathrm{M}$ ammonium acetate (Fisher, UK) adjusted to $\mathrm{pH} 2$ was added to the moist residue in the tube and the mixture shaken and centrifuged as described for step 1.

Step 4: Residual fraction

The solid residue from step 3 was transferred to a high-pressure vessel and digested in aqua regia as described under Sample digestion.

When the sample mass was reduced the amounts of extractants added at steps 1, 2 and 3 were adjusted to maintain the same sample:solution ratio as in the standard protocol. Test portions weighing $1,0.5$ and $0.25 \mathrm{~g}$ were processed in $50 \mathrm{~mL}$ centrifuge tubes, but those with mass 0.125 and $0.0625 \mathrm{~g}$ had to be extracted in 15 $\mathrm{mL}$ centrifuge tubes because it was found that manipulating a small mass in a large vessel was difficult and that errors could easily be introduced due to loss of material. 
To check whether changing the extraction vessel influenced the outcome, $0.25 \mathrm{~g}$ test portions were also extracted in $15 \mathrm{~mL}$ centrifuge tubes.

When the sample mass was reduced in step 4, the amount of aqua regia was adjusted to maintain a constant 1:20 $(\mathrm{m} / \mathrm{v})$ sample:solution ratio. The microwave digestion programme was also modified for sample masses $<0.25 \mathrm{~g}$ to avoid overpressuring and venting of the vessels: only $800 \mathrm{~W}$ was applied and the ramp time to $160{ }^{\circ} \mathrm{C}$ was increased to $20 \mathrm{~min}$.

When sequential extraction was applied to $0.125 \mathrm{~g}$ of BCR CRM 701 supported on an FDMS filter, reagents volumes were $1 / 8^{\text {th }}$ of those used in extraction of $1 \mathrm{~g}$ samples, and the extraction was performed in $15 \mathrm{~mL}$ centrifuge tubes. The same conditions were used for extraction of blank FDMS filters.

\subsection{Analysis}

Digests and extracts of the GLA URM were analysed by ICP-AES using a Perkin Elmer Optima 3000 instrument (Perkin Elmer, Bucks, UK) with AS-91 autosampler, operated at $1300 \mathrm{~W}$ and $40 \mathrm{MHz}$. Multielement reagent-matched calibrants were prepared by serial dilution of $1000 \mathrm{mg} \mathrm{L}^{-1}$ Spectrosol single-element standard solutions (Merck, Poole, UK). Two wavelengths were monitored per element. If inconsistent results were obtained, additional wavelengths were added.

Digests and extracts of BCR CRM 701 were analysed by ICP-MS using an Agilent 7700x instrument (Agilent technologies, Berkshire, UK) with ASX-500 autosampler, operated at $1550 \mathrm{~W}$ and $27 \mathrm{MHz}$. Reagent-matched calibrants were prepared by serial dilution of $10 \mathrm{mg} \mathrm{L}^{-1}$ Agilent multi-element standard solution 2A. Two isotopes were monitored per element, except for Mn which is mono-isotopic. The internal standard was ${ }^{115} \mathrm{In}$.

3. Results and Discussion

\subsection{Pseudototal PTE concentrations}


The pseudototal PTE concentrations in the GLA URM varied with particle size (Figure 1). Particles in the middle size ranges were depleted in all PTE relative to the bulk soil concentrations (Cr $43.2 \pm 3.0$; Cu $111 \pm 5$; Fe $30600 \pm 1200$; Mn $442 \pm 18$; $\mathrm{Ni} 48.8 \pm 7.0 ; \mathrm{Pb} 389 \pm 25$ and $\mathrm{Zn} 177 \pm 11 \mathrm{mg} \mathrm{kg}^{-1}, \mathrm{n}=34$ [23]) whereas coarser and, especially, finer particles were enriched. The PTE concentrations increased as the particle size decreased from 150-250 to $<45 \mu \mathrm{m}$, with the finest fractions containing the highest contents. This is as expected because smaller particles have larger surface area for sorption, and has been reported previously for urban soils e.g. [24]. The relatively high PTE content in the coarsest fractions was perhaps due to the presence of extraneous large particles of anthropogenic origin or aggregation of smaller particles

The finest soil fraction ( $<45 \mu \mathrm{m}$ particle diameter) was selected for the BCR scaledown experiments because - of the fractions available - it contained the material most likely to become suspended in the atmosphere. The coarsest size fraction (500-1000 $\mu \mathrm{m})$ was also extracted for comparison and to investigate whether the presence of a relatively small number of particles in the test portion (possibly $<700$, assuming a particle diameter of $500 \mu \mathrm{m}$ and a typical soil density of $1.6 \mathrm{~g} \mathrm{~cm}^{-3}$ ) would adversely affect the analytical precision.

\subsection{Scale-down of the sequential extraction procedure}

Table 2 presents recoveries of the BCR procedure with respect to the respective pseudototal concentrations for the same particle size fraction. There was a general, though not universal, trend for recovery to decrease when smaller test portions were analysed, especially for the larger particle size fraction. This reflects the operational difficulties associated with handling small samples and the fact that loss of even a tiny amount of material - for example during washing and centrifugation between steps of the extraction - can have a noticeable effect. Ciceri et al. [25] experienced such poor recoveries and high standard deviations when they applied the original BCR protocol to $0.1 \mathrm{~g}$ sediment samples that they abandoned conventional shaking altogether and instead recommended samples be loaded into an empty SPE cartridge for extraction. Although feasible for powdered material such as soil and sediment, this approach is not suitable for APM associated with collection filters. 
The fractionation patterns obtained when the BCR procedure was scaled down are shown in Figures 2 and 3. Results of statistical analysis are provided in Supplementary Table S1 (specifically, one-way ANOVA for test portions of different mass extracted in the same volume vessel, and student t-test at $95 \% \mathrm{Cl}$ for the two $0.25 \mathrm{~g}$ test portions extracted in vessels with different volume) Unfortunately, two of the three replicates of the $<45 \mu \mathrm{m}$ particle size fraction processed in the $15 \mathrm{~mL}$ vessels were lost at step 3. Data presented for the final two steps of this extraction, for the $0.25,0.125$ and $0.0625 \mathrm{~g}$ samples, are therefore based on a single replicate and subject to higher uncertainty than other results reported. It is noticeable that the residual fraction for the $0.0625 \mathrm{~g}$ test portion of $<45 \mu \mathrm{m}$ particles is smaller, for all analytes, than when larger masses of soil were extracted. However, this may simply reflect poor digestion efficiency for the one remaining test portion.

For the conventional $(1 \mathrm{~g})$ test portions the amounts and proportions of analytes found in the various fractions were similar to values reported previously for the GLA URM soil [23]. For the 500-1000 $\mu \mathrm{m}$ particle size, scaling down the BCR extraction without changing the extraction vessel did not have a significant influence on the amounts of analyte extracted, except for $\mathrm{Fe}, \mathrm{Mn}$ and $\mathrm{Pb}$ in step 4, where the concentration decreased as the mass of material extracted decreased. Similarly, for the $<45 \mu \mathrm{m}$ particles, changing the test portion mass but not the extraction vessel generally had little effect on amounts of analytes recovered (except for $\mathrm{Cr}$ and $\mathrm{Cu}$ in step 2, and $\mathrm{Mn}$ in steps 1 and 3, for extraction carried out in the $50 \mathrm{~mL}$ vessels). Interestingly, changing the extraction vessel (but not the test portion mass) did have a significant effect for all analytes. The student t-test (Table S1) failed in almost $70 \%$ of cases. Comparing the amounts of analyte released when $0.25 \mathrm{~g}$ test portions were processed in $50 \mathrm{~mL}$ and in $15 \mathrm{~mL}$ vessels (Figures 2 and 3) it appeared that moving to a smaller vessel improved recoveries, especially for the larger particle size fraction. This emphasises the operation nature of sequential extraction and highlights that even small procedural changes can have an effect on the outcome. There was no marked difference in uncertainty between results for the 500-1000 and the $<45$ $\mu \mathrm{m}$ particle size fractions, nor did uncertainty increase with decreasing sample size, even for the larger particle size fraction. 


\subsection{Application to simulant APM samples on FDMS filters}

Previous studies involving estimation of bioaccessibility have reported extraction of considerable amounts of PTE from FDMS filters, in particular $\mathrm{Zn}$, which is added as a binder during filter production [26]. As shown in Table 3, this was also the case when blank filters were digested in aqua regia or taken through the BCR extraction. Steps 3 and 4 - where partial dissolution of the filter was observed - were particularly affected. The recovery of $\mathrm{Zn}$ from the blank filter by sequential extraction, relative to the average of the two pseudototal values, was 105\%. Because a $\mathrm{Zn}$ compound is an intrinsic component of the FDMS filter - hence cannot be removed by e.g. washing filters prior to deployment (even if routine users of TEOM FDMS apparatus could be persuaded to do so) - the only viable analytical option is blank correction.

Two simulant APM samples, prepared by carefully smearing BCR CRM 701 on FDMS filters, were extracted using the scaled-down BCR procedure and the results compared with certified values. Recoveries for individual steps (Table 4) were generally low except for $\mathrm{Cr}$ and $\mathrm{Pb}$ in step 4 and $\mathrm{Zn}$ in step 3. The latter may be due to the substantial variability in extractable $\mathrm{Zn}$ content in the FDMS filter medium (see Table 3). However, considering the sample mass was small and the considerable contribution to PTE concentrations from the filters, the overall recovery range ( $($ (steps $1-4)=84.2-113 \%$ ) was remarkably good. The fractionation patterns obtained (Figure 4) were similar to certified values and, importantly, would lead to similar conclusions in terms of the potential mobility of analytes contained in the particles.

\section{Conclusions}

This study has shown that the BCR sequential extraction can be scaled down and performed on $0.0625 \mathrm{~g}$ test portions, when the sample:solution ratio recommended in the standard protocol is maintained, but that even minor changes in laboratory procedures such as use of a smaller extraction vessel can affect the results obtained. It is therefore strongly recommended that any modifications to the BCR 
protocol, necessitated for example by application to a new type of sample or use of non-standard extraction apparatus, are carefully evaluated to ensure results obtained by the procedure remain comparable between laboratories.

The scaled-down BCR protocol was successfully applied to BCR CRM 701 supported on FDMS filters, which are used widely in continuous monitoring of ambient APM, giving PTE fractionation similar to certified values. The presence of large quantities of $\mathrm{Zn}$ in the filters represented a significant challenge but could be overcome by blank-correction. The minimum sample mass studied was still approximately an order of magnitude greater than the mg quantities of APM typical obtained during routine use of TEOM-FDMS samplers. Preparing simulant APM samples with lower quantities of CRM proved irreproducible because loss of the fine powder occurred during loading and/or extraction of the filters. However, since analyte levels in the extracts obtained were well above ICP-MS limits of detection, there is scope to process smaller amounts of material, in particular if the particles are partially embedded in the filter medium as would be the case for genuine APM.

Further work will investigate the use of flow-through extraction geometry to minimise sample handling, and application of a non-specific sequential extraction e.g. the chemometric identification of substrates and element distribution (CISED) approach developed by the British Geological Survey [27].

\section{List of abbreviations}

ANOVA analysis of variance

APM airborne particulate matter

BCR Community Bureau of Reference of the European Commission

FDMS filter dynamics measurement system

GLA URM Glasgow urban soil secondary reference material

ICP-AES inductively coupled plasma atomic emission spectrometry

ICP-MS inductively coupled plasma mass spectrometry

NIST SRM National Institute of Standards and Technology standard reference material

PTE potentially toxic element

TEOM tapered element oscillating microbalance 


\section{Disclosure statement}

The authors declare no conflicts of interest.

\section{Funding}

This work was supported by award of a PhD scholarship to BSS from TETFund Nigeria. 


\section{References}

[1] A.M. Ure, Mikrochim. Acta 2, 49 (1991)

[2] J.R. Bacon and C.M. Davidson, Analyst 133, 25 (2008)

[3] A.M. Ure, Ph. Quevauviller, H. Muntau, and B. Griepink, Int. J. Environ. An. Ch. 51,135 (1993)

[4] G. Rauret, J.F. Lopez-Sanchez, A. Sahuquillo, R. Rubio, C. Davidson, A. Ure, and Ph. Quevauviller, J. Environ. Monit. 1, 57 (1999)

[5] S. L. Zhao, Y. F. Duan, J.C. Lu, R. Gupta, D. Pudasainee, S. Liu, M. Liu and J. H. Lu, Fuel 232, 463 (2018)

[6] A.M. Fioroto, L.G.R. Albuquerque, G.A.R. Kelmer, D.G. Silva, R.A.A. Couto, and P.V. Oliveira, J. Agr. Food Chem. 66, 6255 (2018)

[7] M. Jukic, L. Curkovic, J. Sabaric and M. Kerolli-Mustafa, B. Environ. Contam. Toxicol. 99, 524 (2017)

[8] Y.Y. Long, L.F. Hu, C.R. Fang, Y.Y. Wu and D.S. Shen, Microchem. J. 91, 1 (2009)

[9] R. Mogwasi, S. Zor, D.K. Kariuki, M.Z. Getenga and V. Nischwitz, Biol. Trace Elem. Res. 182, 407 (2018)

[10] A. Szymczychz-Madeja, M. Welna and W. Zyrnicki, J. Brazil Chem. Soc. 24, 777 (2013)

[11] K.H. Kim, E. Kabir and S. Kabir, Environ. Int. 74, 136 (2015)

[12] A. Mukherjee and M. Agrawal, Environ. Chem. Lett. 15, 283 (2017)

[13] P. Smichowski, G. Polla and D. Gomez, Anal. Bioanal Chem. 381, 302 (2005)

[14] A. Mukhtar and A. Limbeck, Anal. Chim. Acta 744, 11 (2013)

[15] J. Sysalova and J. Szakova, Environ. Res. 101, 287 (2006)

[16] E.C. Witt, H. Shi, D.J. Wronkiewicz and R.T. Pavlowsky, Atmos. Environ. 88, 90 (2014)

[17] E. Dabek-Zlotorzynska, M. Kelly, H. Chen and C.L. Chakrabarti, Anal. Chim. Acta 498, 175 (2003)

[18] E. Dabek-Zlotorzynska, M. Kelly, H. Chen and C.L. Chakrabarti, Chemosphere 58, 1365 (2005)

[19] Y. Zhai, X. Liu, H. Chen, B. Xu, L. Zhu, C. Li and G. Zeng, Sci. Total Environ. 493, 109 (2014)

[20] Y. Sun, X. Hu, J. Wu, H. Lian and Y. Chen, Sci. Total Environ. 493, 487 (2014)

[21] P. Sipos, C. Choi and Z. May, Chemie de Erde 76, 481 (2016)

[22] Thermo Fisher Scientific, Operating guide for TEOM-FDMS 1405-F ambient particulate monitor, http://www.thermoscientific.com/content/dam/tfs/ATG/EPD/EPD Documents/Product Manuals \&

Specifications/Air Quality Instruments and Systems/Particulate/EPM-manual-1405F.pdf (accessed September 2019).

[23] C.M. Davidson, G.J. Urquhart, F. Ajmone-Marsan, M. Biasioli, A. Duarte, E. Diaz-Barrientos, H. Grcman, I. Hossack, A.S. Hursthouse, L. Madrid, S. Rodrigues and M. Zupan, Anal. Chim. Acta 565, 63 (2006)

[24] F. Madrid, M. Biasioli and F. Ajmone-Marsan, Arch. Environ. Con. Tox. 55, 21 (2008)

[25] E. Ciceri, B. Giussani, A. Pozzi, C. Dossi and S. Recchia, Talanta 76, 621 (2008)

[26] J.A.H. Alpofead, C.M. Davidson and D. Littlejohn, Anal. Methods-UK 8, 5466 (2016)

[27] M.R. Cave, A.E. Milodowski and E.N. Friel, Geochem-Explor. Env. A. 4, 71 (2004) 


\section{Legends for Figures}

Figure $1 \quad$ Variation in PTE content across the particle size fractions of GLA URM. Error bars $=1$ standard deviation, $n=3$

Figure 2 Effect of scale-down of the BCR sequential extraction on the fractionation of chromium, copper, iron and manganese in two particle size fractions of GLA URM

Figure 3 Effect of scale-down of the BCR sequential extraction on the fractionation of nickel, lead and zinc in two particle size fractions of GLA URM

Figure 4 Sequential extraction of two $0.125 \mathrm{~g}$ samples of BCR CRM 701 supported on FDMS filters. 
Table 1 The revised BCR sequential extraction [4]

\begin{tabular}{|l|c|c|}
\hline & Fraction label & Nominal target phase(s) \\
\hline Step 1 & Exchangeable, water- and acid-soluble & $\begin{array}{c}\text { Soluble and exchangeable cations, and, } \\
\text { carbonates }\end{array}$ \\
\hline Step 2 & Reducible & Fe-Mn oxyhydroxides \\
\hline Step 3 & Oxidisable & Organic matter and sulfides \\
\hline Step 4 & Residual & \\
\hline
\end{tabular}


Table 2 Recoveries for sequential extraction of test portions of different mass for two particle size fractions of GLA URM (\%)

\begin{tabular}{|l|l|l|l|l|l|l|l|l|}
\hline $\begin{array}{l}\text { Particle } \\
\text { size } \\
(\mu \mathrm{m})\end{array}$ & $\begin{array}{l}\text { Sample } \\
\text { mass } \\
(\mathrm{g})\end{array}$ & $\mathrm{Cr}$ & $\mathrm{Cu}$ & $\mathrm{Fe}$ & $\mathrm{Mn}$ & $\mathrm{Ni}$ & $\mathrm{Pb}$ & $\mathrm{Zn}$ \\
\hline $500-$ & 1.0 & 95.2 & 100 & 101 & 107 & 94.1 & 105 & 97.6 \\
\cline { 2 - 9 } 1000 & 0.5 & 98.3 & 95.2 & 94.2 & 101 & 91.4 & 101 & 95.8 \\
\cline { 2 - 9 } & $0.25^{\mathrm{a}}$ & 89.9 & 90.2 & 83.5 & 95.9 & 82.7 & 97.1 & 98.3 \\
\cline { 2 - 9 } & $0.25^{\mathrm{b}}$ & 88.6 & 99.6 & 92.2 & 92.7 & 80.9 & 96.0 & 91.4 \\
\cline { 2 - 9 } & 0.125 & 74.6 & 97.9 & 82.2 & 82.4 & 64.1 & 95.5 & 77.4 \\
\cline { 2 - 9 } & 0.0625 & 98.5 & 94.4 & 93.6 & 82.7 & 62.0 & 89.2 & 75.3 \\
\hline \multirow{4}{*}{$<45$} & 1.0 & 94.5 & 96.8 & 88.3 & 92.9 & 89.5 & 96.1 & 98.6 \\
\cline { 2 - 9 } & 0.5 & 90.5 & 93.3 & 90.7 & 95.8 & 92.2 & 99.8 & 88.5 \\
\cline { 2 - 9 } & $0.25^{\mathrm{a}}$ & 87.4 & 94.3 & 90.3 & 100 & 96.1 & 104 & 107 \\
\cline { 2 - 9 } & $0.25^{\mathrm{b}}$ & 93.4 & 95.4 & 94.5 & 93.3 & 95.2 & 91.0 & 86.5 \\
\cline { 2 - 9 } & 0.125 & 84.0 & 98.7 & 86.5 & 94.1 & 82.6 & 92.0 & 86.3 \\
\cline { 2 - 9 } & 0.0625 & 48.4 & 106 & 83.1 & 103 & 69.6 & 106 & 83.3 \\
\hline
\end{tabular}

Recovery $=(\Sigma($ steps 1-4)/pseudototal concentration $) \times 100)$; ${ }^{\text {a }}$ processed in $50 \mathrm{~mL}$ vessel in the same batch of extractions as the 1 and $0.5 \mathrm{~g}$ test portions; ${ }^{b}$ processed in $15 \mathrm{~mL}$ vessel in the same batch of extractions as the 0.125 and $0.0625 \mathrm{~g}$ test portions. 
Table 3 Amounts of potentially toxic elements extracted from blank FDMS filters using aqua regia and the BCR sequential extraction ( $\mu \mathrm{g}$ per filter)

\begin{tabular}{|l|c|c|c|c|c|}
\hline & $\mathrm{Cr}$ & $\mathrm{Cu}$ & $\mathrm{Ni}$ & $\mathrm{Pb}$ & $\mathrm{Zn}$ \\
\hline Pseudototal & $3.55 \pm 0.11$ & $1.09 \pm 0.08$ & $0.51 \pm 0.04$ & $0.75 \pm 0.05$ & $1140 \pm 16$ \\
Batch 1 & $(3.2)$ & $(7.7)$ & $(8.2)$ & $(6.2)$ & $(1.4)$ \\
\hline Pseudototal & $3.21 \pm 0.27$ & $2.57 \pm 0.40$ & $0.66 \pm 0.07$ & $0.73 \pm 0.07$ & $1060 \pm 78$ \\
Batch 2 & $(8.5)$ & $(15)$ & $(9.9)$ & $(9.2)$ & $(7.4)$ \\
\hline BCR Step 1 & $<$ LOD & $<$ LOD & $<$ LOD & $<$ LOD & $3.17 \pm 0.49$ \\
& & & & & $(16)$ \\
\hline BCR Step 2 & $<$ LOD & $<$ LOD & $<$ LOD & $0.007 \pm 0.004$ & $1.65 \pm 0.72$ \\
& & & & $(57)$ & $\{44)$ \\
\hline BCR Step 3 & $0.861 \pm 0.474$ & $0.0742 \pm 0.0366$ & $0.310 \pm 0.274$ & $0.105 \pm 0.031$ & $243 \pm 101$ \\
& $(55)$ & $(49)$ & $(88)$ & $(30)$ & $(42)$ \\
\hline BCR Step 4 & $2.87 \pm 0.29$ & $1.10 \pm 0.13$ & $0.435 \pm 0.031$ & $0.566 \pm 0.057$ & $908 \pm 168$ \\
& $(10)$ & $(12)$ & $(7.2)$ & $(10)$ & $(18)$ \\
\hline
\end{tabular}

Mean \pm one standard deviation, $n=6$ for pseudototal; $n=5$ for sequential extraction, \% RSD values in parenthesis 
Table 4 Recoveries for sequential extraction of $0.125 \mathrm{~g}$ samples of BCR CRM 701 supported on FDMS filters (\%)

\begin{tabular}{|l|l|c|c|c|c|c|}
\hline & & $\mathrm{Cr}$ & $\mathrm{Cu}$ & $\mathrm{Ni}$ & $\mathrm{Pb}$ & $\mathrm{Zn}$ \\
\hline Step 1 & Filter 1 & 83.3 & 77.1 & 71.5 & 79.8 & 81.7 \\
\hline & Filter 2 & 85.4 & 80.7 & 75.1 & 80.6 & 87.0 \\
\hline Step 2 & Filter 1 & 80.1 & 80.0 & 87.4 & 82.9 & 102 \\
\hline & Filter 2 & 81.6 & 83.6 & 88.7 & 83.8 & 105 \\
\hline Step 3 & Filter 1 & 88.6 & 134 & 141 & 118 & 142 \\
\hline & Filter 2 & 64.8 & 98.1 & 101 & 81.1 & 145 \\
\hline Step 4 & Filter 1 & 194 & 73.1 & 88.4 & 137 & 81.4 \\
\hline & Filter 2 & 161 & 70.1 & 85.3 & 123 & 82.0 \\
\hline$\Sigma$ (steps 1-4) & Filter 1 & 113 & 89.7 & 93.5 & 89.3 & 92.5 \\
\hline & Filter 2 & 91.9 & 84.2 & 87.1 & 86.7 & 96.2 \\
\hline
\end{tabular}

Recovery = found/certified (or indicative) $\times 100$. Values for $\mathrm{Zn}$ in Step 3 and Step 4 were blank corrected due to the high filter blank (see Table 3) 


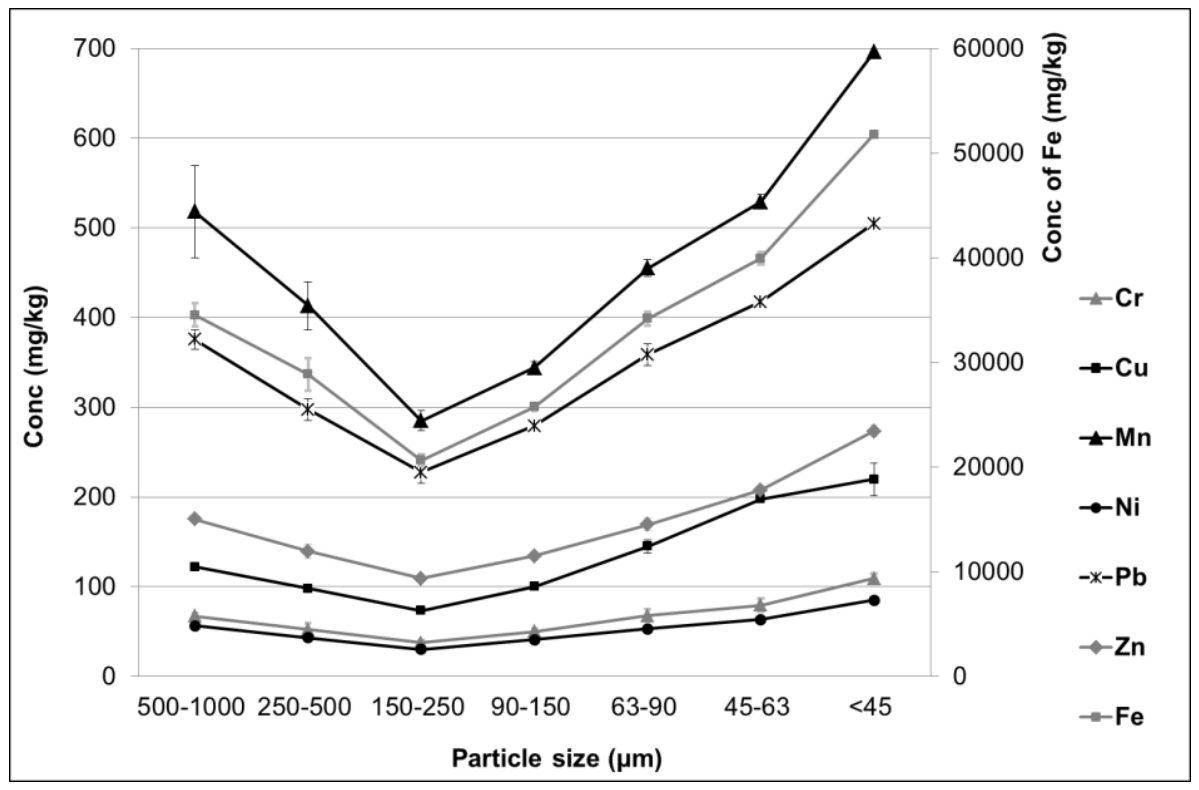




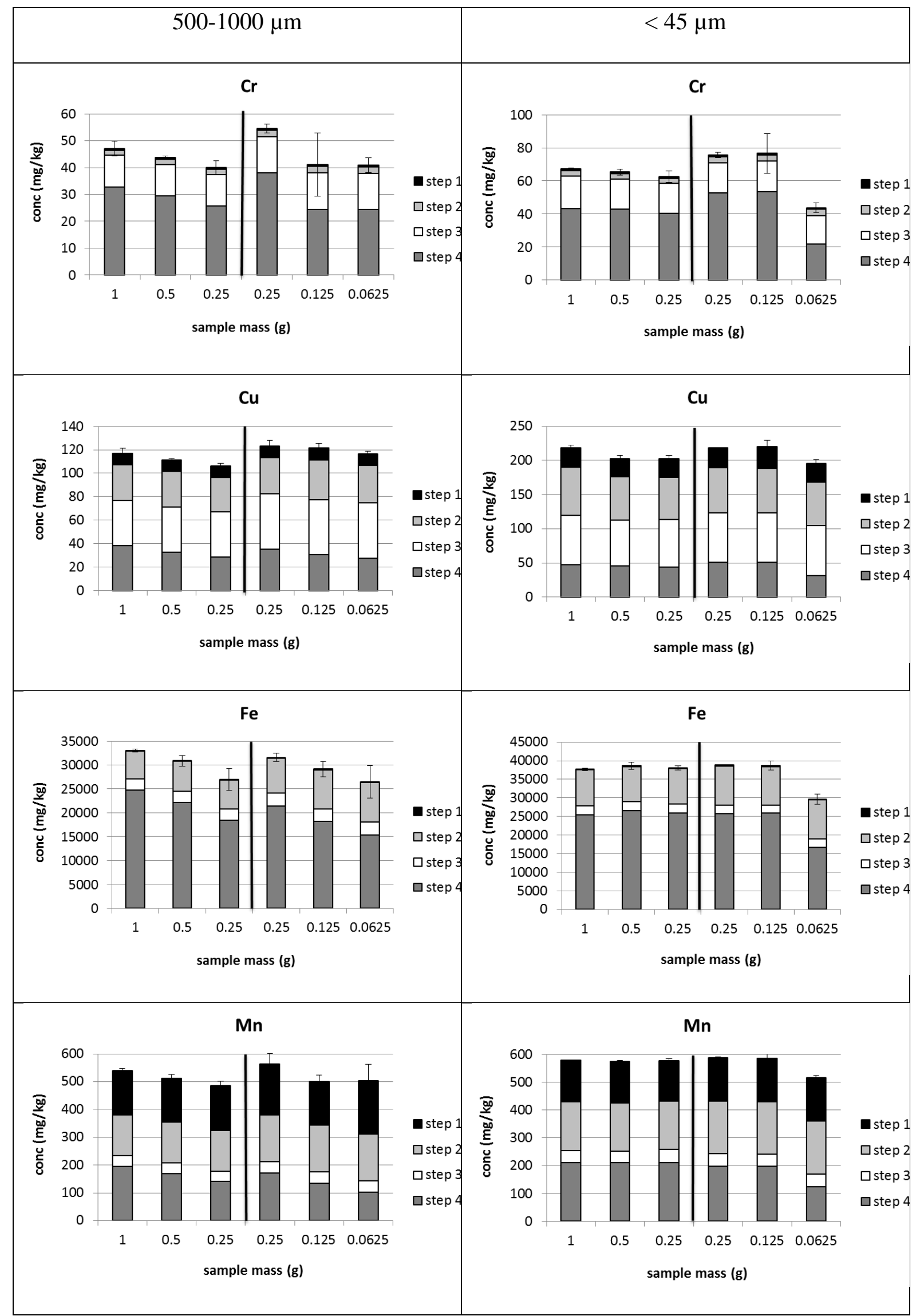

The vertical line separates extractions performed in $50 \mathrm{~mL}$ vessels from those performed in $15 \mathrm{~mL}$ vessels 


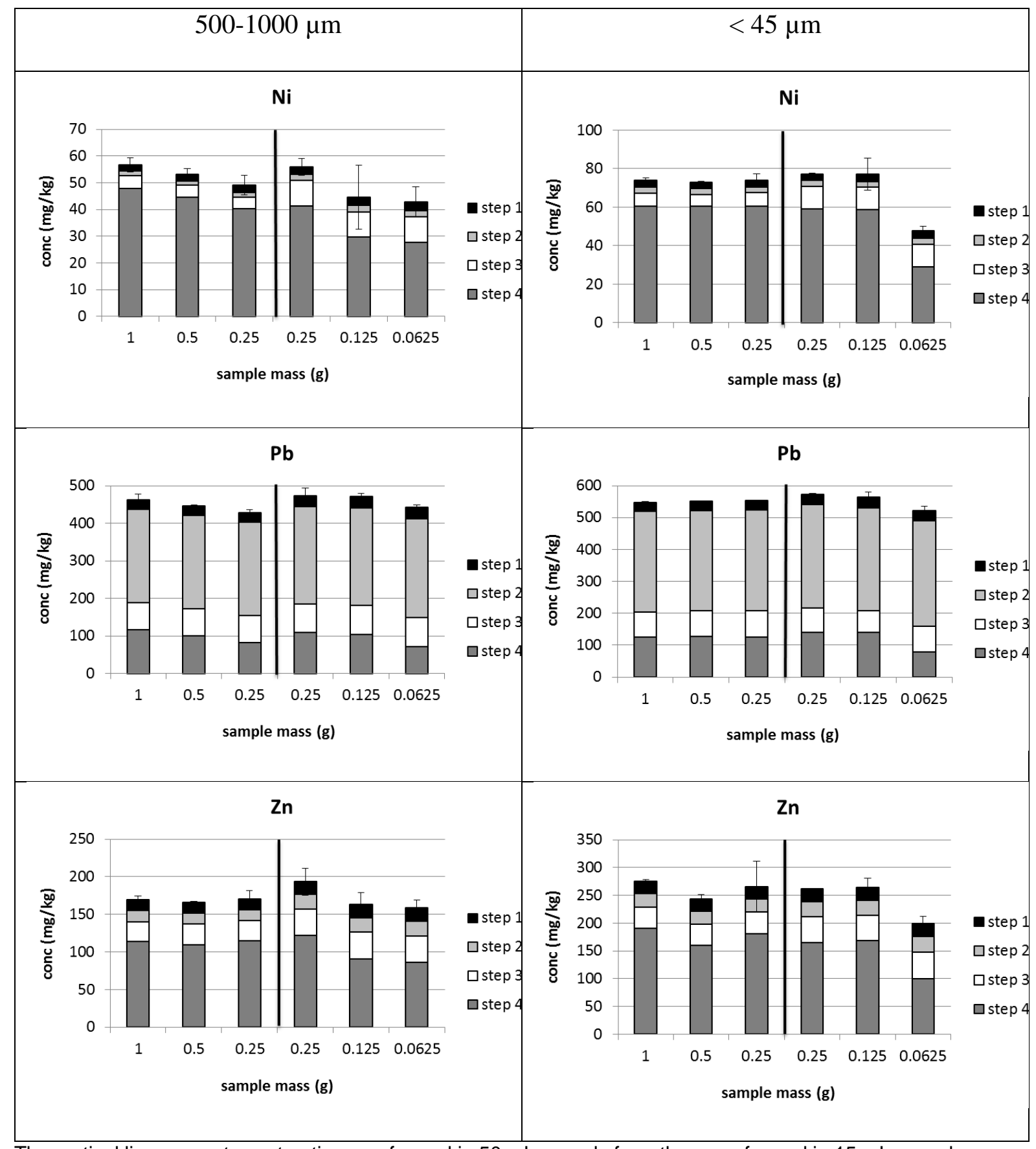

The vertical line separates extractions performed in $50 \mathrm{~mL}$ vessels from those performed in $15 \mathrm{~mL}$ vessels 


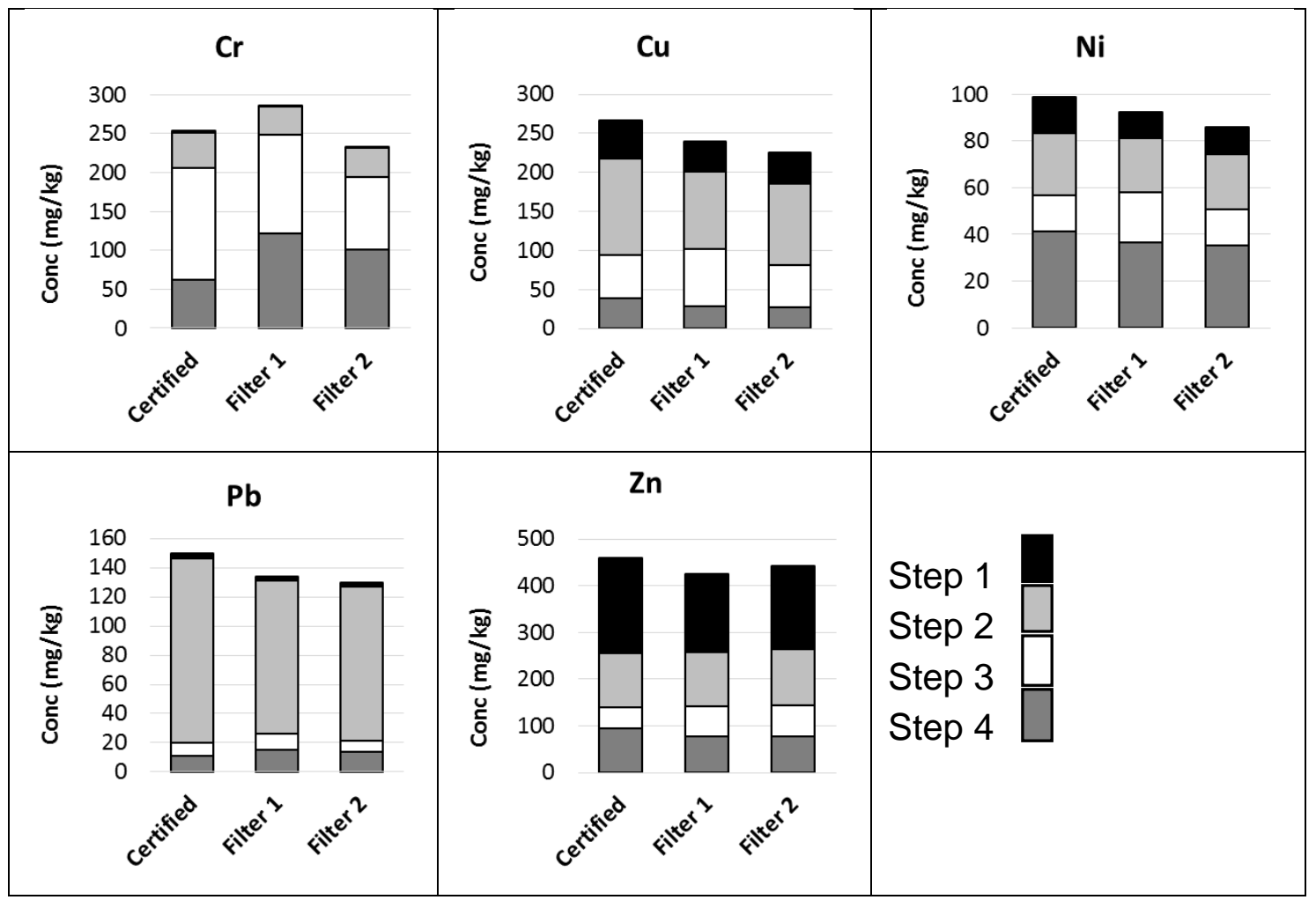

Results for $\mathrm{Zn}$ in steps 3 and 4 have been blank-corrected 